\title{
THE LATE SIR EDMUND TAYLOR WHITTAKER, M.A., Hon.F.F.A., F.R.S., Sc.D., LL.D.
}

Edmund Taylor Whittaker was born on 24th October 1873 of an old Lancashire family. Educated at Manchester Grammar School he went up to Trinity College, Cambridge as a Scholar in 1891. He graduated B.A. in 1895 and the next year he was elected a Fellow of Trinity College. Like many other eminent men he was First Smith's Prizeman although Second Wrangler. In 1904 he was elected a Fellow of the Royal Society at the early age of 31 and the following year he was appointed Royal Astronomer of Ireland and Professor of Astronomy in Trinity College, Dublin.

In 1912 he came to Edinburgh University as successor to Chrystal in the Chair of Mathematics with a great reputation as a mathematician and he soon showed that he was an inspiring teacher as well. He took a full share in the wider work of the University, acting as Dean of the Faculty of Arts for a period and as a Senatus Assessor on the University Court. He was knighted in the New Year Honours of 1945 and retired in 1946.

Whittaker was one of the great mathematical scholars and teachers of the world. He was President of the Mathematical Association 1920-21, of Section A of the British Association 1927, of the London Mathematical Society 1928-29, of the Royal Society of Edinburgh 1939-44 and several times of the Edinburgh Mathematical Society. He was Rouse Ball Lecturer at Cambridge 1926, Hitchcock Professor University of California 1934, Riddell Lecturer Durham University 1941, Guthrie Lecturer Physical Society 1943, Donnellan Lecturer Dublin University 1946, Tarner Lecturer Cambridge University 1947, Herbert Spencer Lecturer Oxford University 1948, Larmor Lecturer Royal Irish Academy 1948 and Eddington Lecturer Cambridge University 1951. He was awarded the Sylvester Medal of the Royal Society in 1931, the Cross pro Ecclesia et Pontifice in 1935, the De Morgan Medal of the London Mathematical Society in 1935 and the Copley Medal of the Royal Society in 1954. He was an Honorary Fellow of Trinity College, and LL.D. of St. Andrews University and the University of California, an Hon.Sc.D. of Dublin University and an Hon.D.Sc. of London, Manchester and Birmingham Universities and of the National University of Ireland. He was elected an Honorary Fellow of the Faculty in 1918. 
As a lecturer Whittaker was outstanding. His clear diction, his felicity of language and his enthusiasm could not fail to evoke a response in the hearer. And he was a master of the apt and vivid illustration. He had, too, one useful accomplishment which was greatly admired, and gratefully accepted, by his students-he could write rapidly and clearly on a blackboard. He also took a keen personal interest in his students. His house in George Square saw many social gatherings and many a personal interview there has determined a student's whole future career.

Whittaker's interests were equally divided between Pure and Applied Mathematics. Before he was 30 he had published Modern Analysis and Analytical Dynamics. The Edinburgh School was one of the few in this country which gave a regular course on the Mathematical Theory of Probability. In 1913 shortly after his arrival in Edinburgh, Whittaker established the Mathematical Laboratory where the student was initiated into the practical (mainly arithmetical) work of dealing with numerical data. In his preface to The Calculus of Observations he says that the book represents courses of lectures given by him "to undergraduate and graduate students in the Mathematical Laboratory of the University of Edinburgh, and may be regarded as a manual of the teaching and the practice of the Laboratory ". He also acknowledges his debt to Lidstone to whom " mainly it is due that the book is so rich in theorems and methods derived from actuarial sources, with which mathematicians are not usually well acquainted".

The friendship between Whittaker and Lidstone bore other fruit. It was largely due to these two men that the Diploma in Actuarial Mathematics was established at Edinburgh University in 1918. In their Report for that year " The Council gratefully acknowledge the intereşt taken in this matter by Professor Whittaker, and the great assistance he has given them".

On 14th November 1919 Whittaker read a paper to the Edinburgh Mathematical Society on "A new method of graduation" (Proc. Edin. Math. Soc., 1922-1923) which was developed in a paper to the Royal Society of Edinburgh on 14th January 1924 (Proc. Roy. Soc. Edin., 1924). The method was an attempt to find a sounder theoretical basis than that provided by summation formulae. The essence of the method and Prof. Aitken's solution of the difference equation are given in The Calculus of Observations (1926 Edition), pp. 303 to 316.

In 1920, Whittaker read before the Faculty a paper "On Some Disputed Questions of Probability" (T.F.A. 8, p. 163), in effect a 
defence of the theory of Inductive Probability as propounded by Bayes and Laplace and the Principle of Compound Probability. The paper is a good example of Whittaker's lucid style and searching criticism. Whether it can be considered the last word on the subject is another matter. This is the only paper he delivered to the Faculty, but Whittaker from time to time in the years that followed attended Faculty meetings and took part in discussions.

In his later years Whittaker was much concerned with the more philosophical aspects of modern mathematical theory and physical knowledge and he produced several volumes on this subject. After his retirement, however, he rewrote his brilliant History of the Theories of Aether and Electricity (first published in 1910) and followed this with a second volume covering the developments to the present time-a colossal undertaking involving wide reading and accurate understanding.

Whittaker's interest in the Faculty was always keen and many of the present generation of Fellows owe much to the inspiration and gracious friendship which they received in such large measure from him. He had been looking forward to taking part in the Centenary celebrations but it was not to be. He became ill early this year and died on 24th March. To Lady Whittaker, his oldest son who is a Fellow of the Faculty, and the other members of the family we offer deep and respectful sympathy.

K. K. W. 